\title{
Wangfuzhi’s View of Classical Enlightenment
}

\author{
ZENG Mei-zhu \\ Yunnan Honghe College, Meng Zi, China
}

\begin{abstract}
In recent years, with the prevailing of Chinese traditional culture, the related "classic education (经典教育 jingdianjiaoyu)" debate ensued. Some scholars strongly oppose the "classical education” and think that make children memorize mechanicallyand forced recite, without understand about Confucian classes deviate from the modern “children's center-based education” and “ideas violate scientific” and to be "an ancient and retrogression”, “ignorance of cultural conservatism”. They advocating that “things other than children's lives cannot be forcibly entered into the lives of children," otherwise it will be "a killing of childhood innocence and stifling the lives of children”, and imprisonment of children's life. To sum up this fierce argument, the main issues of debate are generally not out of the following four aspects: (1) why do we need classic enlightenment? (2) the purpose and utility of the classic enlightenment? (3) the content and methods of classic enlightenment? (4) the timing of the classic enlightenment? In response to these four points of view, Mr. Wangfuzhi, who was 400 years ago, also put forward his own ideas. This article is not intended to participate in this controversy. Instead, it wants to understand Wangfuzhi's “ideas of classical enlightenment” to understand how the ancients advocated these four issues. For modern people's reference.
\end{abstract}

Keywords: Wangfuzhi, the purpose, utility, content, method and timing of the classical education or enlightenment, Kant

\section{Foreword}

In recent years, with the prevailing of Chinese traditional culture, the related "classic education" debate ensued. To sum up this fierce argument, the main issues of debate are generally not out of the following four aspects: (1) why do we need classic enlightenment? ${ }^{1}$ (2) the purpose and utility of the classic enlightenment? (3) the content and methods of classic enlightenment? (4) the timing of the classic enlightenment? In response to these four points of view, Mr.Wangfuzhi, who was 400 years ago, also put forward his own ideas. From following these four themes, let's see how the idea of Wangfuzhi?

\section{Why do We Need Classic Enlightenment?}

In the theory of human nature, Wangfuzhi inherited the traditional Confucian idea "the theory of goodness

\footnotetext{
ZENG Mei-zhu, Ph.D., Associate Professor, Political science and Institute of international relations, Yunnan Honghe College. ${ }^{1}$ Why "enlightenment" is used instead of "education" because "education" generally refers to the teaching of knowledge and aims to become an expert, but the term "enlightenment" is unique to Chinese traditional culture. Its difference with "education" is that it does not merely impart knowledge, but the main purpose is to make people complete virtue, become a superior man, and become a real human being.
} 
of human nature (性善论xingshanlun)", but also absorbed ZhangZai's ideas of "nature of Heaven and Earth (天 地之性tiandizhixing)" and “physical nature (气质之性qizhizhixing)" and Zhu Xi's "nature of mandate of Heaven (天命之性tianmingzhixing)” and “physical nature”. He developed the distinction between his so-called “congenital nature (先天之性xiantianzhixing)” (endowment of material force) and “posterior nature (后天之性 houtianzhixing)” (practice). He thinks that human nature was not determined at birth, and that completement must be brought into full play by posteriorcultivation and practice. Therefore, he put forward the following theory: “nature growsdaily and achieves completion daily (性日生日成xingrishengricheng)”, “complete nature must basics to inherit goodness (继善成性jishanchengxing)”, “complete nature with your practice (习与性成 xiyuxingcheng)" and other ideas. It is believed that one must consciously inherit the pure and highest excellence of original nature and continue to dig, expand, and develop it. Only in this way can he become a truly person of perfect, that is, what he calls the “complete nature (成性chengxing)”, as he said:

Mandate of Heaven got highlighted, then the physical nature will be hide.If the mandate of Heaven got highlighted, then to inherit it is goodness. Only smart and wisesage whomastered virtue of Heaven knows it. If hide in the physical endowment, in other words, the nature must to be complete, if you give up, the nature will be lose, itwill not reflect. You must to return your nature. (Wang, 2011d, p, 262)

On the other hand, Wangfuzhi also attaches great importance to the development of the posterior "practice (习xi)" and the so-called “complete nature with your practice”. He thinks that if people live in unhealthy customs for a long time and do not know toinheritgoodness of Heaven, they will gradually form unhealthy habits that will affect people’s behavior and”moral character (品行 pingxing)”. As a result, their nature will not be able to be good highlighted and developed. As he said:

Practice have a great effect on people, if the ear is stuck by what it hears, its inherent ability to hear clearly will be blinded; if the eye is stuck by what it sees, its inherent ability to see clearly will be blinded. When one begins speak and act, his parents' and brothers'influence is important. When one enters the stage of learning how to distinguish between good and bad, his related hometown people and relatives guide him.If his senses of ears and eyes, and his mind moved away,this prevented him from seeing a thing as big as Mount Tai and hearing a sound as loud as thunder. (Wang, 2011c, p. 390)

In other words, Wangfuzhi thinks that the serious contamination of social and environmental customs can change people's eyes and ears and mind functions, immersing people in vulgarity and make them being unable to extricate themselves. It can be seen that Wangfuzhi can deeply feel the seriousness of the erosion of human nature in the world of pollution and vulgar evil of customs. Because people are easily born in there without knowing it, not only do not know consciously, he will easy to flow in the vulgar and practice in it, this resulting in the decline of the moral character, the human nature became unhealthy, and be hide. As he said:

If people unfortunately lose a good enlightenment, he will fall into unhealthycustoms, what he heard was not can speech of the human, what he saw was not can to do of the human. He was influenced by various things of hometown, if aspiring people want to save these loses after them grow up. It is impossible to succeed without changing inside and outside. (Wang, 2011c, p. 494)

It is difficult to save people's minds once they get lost. This is called "habit accumulation hard to return (积 重难返 jizhongnanfan)”! Even if there are serious teachers and useful friends, they can’t be exhorted. There are heavy penalties and punishment that cannot be corrected. Especially after reaching adulthood, the character of the 
person has been established, and again to make it back to its "pure and highest excellence of nature (纯然至善 之性 chunranzhishanzhixing)” and own accord, it is really necessary to make great efforts!

Therefore, Wangfuzhi advocated not only that human beings should be aware of the goodness of nature, but more importantly, they should be able to continuously maintain and conserveand expand their own natural good so that they will be able to reach a “spheres of livingof achieved propriety (圆熟之境 yuanshuzhijing)” and be fully demonstrated. Play its usefulness for real life. From this it can be seen that it is very necessary to give "classics enlightenment” to people, and it will be the foundation on which people can "inherit goodness (继善 jishan)” and then “complete nature (成性chengxing)". That is, “classic enlightenment” is the development of human nature projects, starting from the human nature; make nature and emotions of peoplecan make the best of it, and to send people become a truly perfect person.

In fact, western philosophy Kant also said: “the mean of Creator (天意tianyi)” wants you to bring good out of yourself, and the Creator says to human: "I have equated you with all the endowment to reach the highest excellence, and you now have to come up with it yourself. So whether you are happy depends on yourself" (Kant, Zhao, \& He, 2005, p. 7). It can be seen that the "classical enlightenment" to people is not "strangling on human nature and imprisonment of life”. Instead, we are going to develop theinstincts inherent in human beings and we can see that the purpose of enlightenment is ostensibly being a “complete virtue (成德chengde)”, but in essence it is hoped to full play the nature of one's own accord. This is what Wangfuzhi called the process of "completenature". That is to say, he thinks that mankind should make its full natural endowment of material force gradually emerge from itself through his own efforts, all of which must be motivated by the posterior "classic enlightenment”.

\section{The Purpose and Utility of the Classic Enlightenment}

Generally summed up the purpose and utility of the enlightenment of Wangfuzhi, there are four: (1) illustrious Dao (明道 mingdao) and “exhaustivestudy of principle (穷理 qiongli)”, in order to “fully develop one’s nature (尽性 jingxing)”; (2) change the physical endowment, in order to “complete his natural powers (成 其才 chengqicai)”; (3) complete virtues, in order to highlight his nature adequately; (4) enlighten the people and complete good folk customs (化民成俗 huaminchengsu), to “eliminate of disputes, without speaking (不言靡 争 buyanmizheng)".

\subsection{Illustrious Dao and Exhaustivestudy of Principle, in Order to Fully Develop One's Nature}

ChuanShan said "the utilityof the Dao is teaching", but what is "the utility of Dao"? His own interpretation is "people who execute Dao (行道 xingdao), in order to complete the transformation (成化 chenghua), People who highlight Dao can to make the teachings (立教 lijiao)” (Wang, 2011e, p. 483). That is, ChuanShanthinks that the sageis the man who clear and understand "the Dao of Heaven and Earth (天地之道tiandizhidao)". The sageunderstand and awakenthe Dao of Heaven and Earth turning into the world, thus to execute Dao of Heaven and Earth and transformation the things of the world. And since enlightenment is established by Dao of Heaven and Earth, its purpose is nothing more than to let people through it to understand the way of Heaven and Earth; as he himself said:

The teachings of sage is only for exhaustive study of principle through the things, and behold the Dao through the Article (sage’s). (Wang, 2011h, p. 570) 
Teachingsare aim to practice Dao, every people should do their best to achieve Dao. The Dao highlight on enlightenment, because the Dao can't abandoned, this is, must to fully develop the enlightenment.Teachingsarebased on the Heaven, inherent human nature, and the best way to understand the Dao, is to practice it. (Wang, 2011h, p. 105)

“Exhaustivestudyof principle through the things (即物穷理jiwuqiongli)”, “Behold the Dao through the Article (即文见道jiwenjiandao)” is the purpose of the sage's enlightenment. What is the utility of "illustrious of the Dao"? As it is said, Dao be highlighted, then teachings be manifest. Understand the Daocan manifests the truth of the enlightenment is based on the Dao of Heaven and inherent in human nature, so that human beings canfully develop their inherent nature through the function of enlightenment, thus what they have done have the reason why it should be done. The so-called "the best way to develop the Dao is to practice it" explained that people have to fully develop the Dao after they understand the Dao, so that teachings can be highlighted, so we say “Dao can't be abandoned”. If Dao was excepted, the teachings will not wide spread, Dao of Heaven can't be highlighted.

Therefore, for ChuanShan, there is no Dao is outside of things, no things is outside of Dao, enlightenment cannot be separated from the Dao, "practice Dao is named as teachings". As he himself said:

No Dao is outside of things, no thingsare outside of Dao, trying to things, is that accommodate Dao. Etiquette, ceremony, standard, rule, all have a certain normative rule, maintain them respectfully, sincerely face them, cultivate them leisurely, then nurture in the rule of Heaven, and make them savor the specification on their mind, then external temptations cannot intervene. Thus there is no more higher degree of spiritual and transforming powers (神化shenhua) is not in this daily trivial matter and practice. (Wang, 2011h, p. 971)

The teachings of “Six ConfucianClassics (六经liujing)" are all about exhaustively studyprinciple and fully develop one's nature, nature is satisfied. The people of made teachings get the real means, enlighten learners rule with most equilibrium and highest just. So the goodness of nature of people all will be grow up, then the customs will be good. If classic is positive, the commonpeople will be enlightened, the heresy and improper theory do not influence and disturb him. (Wang, 2011a, p. 1173)

In other words, human beings have the "rule of most equilibrium and highest just (大中至正之矩 dazhongzhizhengzhiju) of Dao" in the nature, the so-called "rule of Heaven (天则 tianze)”. Therefore, the purpose of enlightenment is to require people to practice, and to nurture in the rule of Heaven, in order to illustriousthe Dao,that is in their mind and then to raise its "highest goodness (至善 zhishan)" of nature; this is the so-called “exhaustive studyprinciple, in order to fully develop one’s nature (穷理以尽性 qiongliyijinxing)”. Understanding the truth of Heaven and Earthis fully develop people's nature.Such, that human beings can be made to exert their inherent qualities inside in humanity that etiquette, and ceremony based on nature. The customs, however, are naturally perfect and disappointing calamity, while the country is self-righteous, and the theory of heresies can't enter.We can see, “illustrious Dao" is very important in terms of enlightenment, ChuanShan's so-called" the difference of good and bad dignified in the world, and the people get enlightened" (Wang, 2011a, p. 1362). “If the Daocan’t be highlighted, people’s like and dislikes will be selfish, and there will be an unhealthy custom” (Wang, 2011a, p. 538). “There are never kingly way (王道 wangdao) can rise without enlightenment highlight” (Wang, 2011h, p. 570). They are all instructions, the manifest or not manifest of Dao is the validation of whether the enlightenment is well highlighted. 


\subsection{Change the Physical Endowment, in Order to Complete his Natural Powers}

Because human being has different “endowment of material force (禀赋 bingfu)”, his nature and emotion (性情 xingqing) has difference in degree of smartnessand clumsy. Therefore, one of the purposes of enlightenment is to “change the physical endowment (变化气质 bianhuaqizhi)" and rectify his nature and emotion and returning to norm of nature. For example, ChuanShan said:

Probably from people born in this world, the Creator has not given no people humanity, righteousness, propriety and wisdom of nature, but there are some people's endowment of material force cannot be the same. So there are not everyone know all his nature and complete it. If smart and wise people who can fully develop his naturewas born, then Heaven willmandate him as the teacher of millions of people, let him govern and teach them,and make them return to their nature. (Wang, 2011h, p. 570)

What teachers teach can stop bad, but sincerity and clear do not rely on enlightenment, everyone can become Yao, Shun, everyone can corresponds tothe Heaven. (Wang, 2011b, p. 130)

That is, Chuan Shan thinks that due to the difference of human's physical endowment and endowment of material force, so have their nature and emotions of the partial, but not "all can know what they have in their nature and improve themselves"; and enlightenment is that sage with smart and wise and can fully develop his naturewho to undertake of Heaven's mandate created to rule people. His purpose is to make people change the physical endowment and rectify their incorrect, so that the good will be raised and the wicked will be stopped, so that everyone can returning to their nature as if Yao, Shun and send their virtue corresponds to Heaven.

But change the physical endowment, rectify his incorrect nature and emotionfor returning to positive, what is its purpose? As mentioned before, people have different endowment of material force, so their natural powers will be different. The purpose of enlightenment is to enable people to fully display their good powers of nature and achieve their different effects. AsChuan Shan said:

After modify and prepared of sage, the way of enlightenment are all developed fully in Six ConfucianClassics, ruler or teachers use it as teachings. Send learners accustomed and conserve it. The effective of changing the physical endowment, in order to complete his nature is like this. (Wang, 2011a, p. 1172)

Enlightenment implement, then people's wise be enlightened, system be established, then people's ability will be developed, livetool complete, then the people's live be comfortable. Sospiritual person become more and more agility, fools do not limited in his endowment of material force. (Wang, 2011a, p. 711)

It can be seen that though the nature of humanity is universal, it is limited to the difference between endowment of material forcehas between on spirituality and stupidity. The purpose of enlightenment is to develop the intelligence of people of different natural powers generally. So spiritual person become smarter, and stupid people are not confined to their natural materials, allowing them to fully exert their different qualities and utilities. The so-called "the natural powers all will be useful"; as long as people can get their obverse of nature and emotions, and in its natural endowment, to hair glow its speciality, should be able to accomplish its effectiveness for the world.

In addition, enlightenment can also be disposition for different people, but its ultimate goal is to return to the original nature of good nature, and to hair glow its' powers; as ChuanShan said:

Enlighten a “superior man (君子 junzi)” of Dao, who cultivate its profound meaning, the stubborn and violence part of his minds disappears day by day, if he rules the common people and definitely will love them.Enlighten an "inferior 
man (小人 xiaoren)” of Dao, who feels its content, the naughty and indulgent of physical endowment get change, let him serve the leader, and he will be easy to tamed. (Wang, 2011h, p. 904)

The superior man all can be given with beauty of equilibrium and harmony.The inferior man all can be given with transforming of pure goodness. (Wang, 2011a, p. 905)

In other words, enlightenment can target people of different physical endowment to rectify their incorrect nature, allowing the superior man's stubborn and violence part of his minds disappears day by day on originally nature, and an inferior man's naughty and indulgent of physical endowment get change; but its ultimate goal is for people to change their physical endowment, so that the superior man can get "beauty of equilibrium and harmony (中和之美zhonghezhimei)”, and the inferior man has “pure mind of goodness (纯良之心 chunliangzhixin)", and all can be returning to obverse of nature and emotions. Based on this foundation, people can fully develop their natural powers and can be reasonable without losing their true position in what they do; and this should be the best proof that "you can hair glow your speciality without sacrificing your natural nature".

\subsection{Complete Virtues, in Order to Highlight His Nature Adequately}

As mentioned earlier, enlightenment is a manifestation of the sage’s “Great Cause (盛德大业shengdedaye), so “teachings" are the morality presentation of the sage, is so-called “virtue teachings (德教dejiao)". And its purpose is nothing more than to “use virtue to move morality (以德感德yidegande)”, send people from the enlightenment to perceive the virtues of the sage, spontaneous rule their will and conserve their virtue; asChuanShan said:

According to things of worlds, to formulate the highestteachings.All this is used for taking the standard as the just, pre-conserve and pre-reserve morality. (Wang, 2011a, p. 528)

A superior man is the so-called "to conserve the people with the way of Heaven". The virtueteachingsdisplay on self-love. Others will not alienate with him when he is close to, others will not neglect him when he respect to them. (Wang, 2011f, p. 58)

"conserve the people with the way of Heaven (以天道养人yitiandaoyangren)" is the so-called "virtue teachings" in ChuanShan. Its purpose is to conserve and reserve people's morality through enlightenment so that people can consciously and spontaneously love their original nature. For those who spontaneously love their virtue, they can love what they should love and respect what they should respect, and all the things they do can be reasonable. In this way, which make people easilyaccessible and respectablenaturally. This is the so-called "the people of having moral".

What is "virtue" or so-called "having moral”? ChuanShan said so:

Behold perception in mind by Practice Dao is called the “virtue”. (Wang, 2011a, p. 927)

"Virtue", people get it from the Heaven, and emotion can be arrived, then natural powers can be fully developed actually. Even some trivial things, if you do it without according to perception of mind, you can never practice it. (Wang, 2011a, p. 670)

Get true principleinmind, is called”having moral”. (Wang, 2011a, p. 607)

That is to say, "virtue" must be practiced in behavior and can getperception in mind; and the "virtue teachings" of the sage, in addition to making it possible for people to get the truth of principleand hopes that they 
will percept it in mind, and practice this “virtue of heart” (心之德xinzhide) in the implementation of daily behavior. Because, as emphasized by ChuanShan, "virtue" is derived from the Heaven and inner in the heart of human being, and if it is inner the heart and cannot be perceived profoundly, the so-called "root of obtain of the mind”, that nature of human cannot be fully highlight, it is called “emotioncan’t be arrive (情不至 qingbuzhi)” and “natural powerscan’t be fully developed (才不尽 caibujin)”. Such as “Book of Rites (《礼记》 liji)” said “The virtue, is the beginnings of nature”.ChuanShanannotate it as "humanity (仁 ren), righteousness (义 yi), propriety (礼 li), wisdom (智 zhi), all in the nature, and display as virtue, so therefore”beginnings (端 duan)” (Wang, 2011a, p. 927). "Virtue" is a manifestation of inner nature, and ifthe nature it is not manifested, then virtue is not achieved; the so-called "teachings finished thenvirtue achieved, virtue achieved thenteachings respected, and naturecan practice authenticity". It can be seen that the objective of enlightenment is "complete virtue (成德 chengde)” In essence, however, it is hoped that the original human nature will be fully highlighted. Therefore, "virtue” and "teachings" are mutually reinforcing, highlight and validated.

\subsection{Enlighten the People and Complete Good Folk Customs, to Eliminate of Disputes, Without Speaking}

The purpose of enlightenment mentioned earlier is to "illustriousDao (明道mingdao), to change physical endowment" and "complete virtue" and so on. This is from the subjective view of the individual. If objectively speaking, the purpose of enlightenment should be "enlighten the people and develop good folk customs," make this country not calamity, and peace and positive spontaneously without the soldier and punishment; as ChuanShan said:

“Teachings”, points to the things of enlighten people and complete good folk customs. (Wang, 2011a, p. 948)

The teachings executing, bad folk customs get correcting, all the thing develop very smooth, the calamity will not happen. (Wang, 2011a, p. 1518)

“Disappointing calamity (祸乱不兴 huoluanbuxing)” and then “world be peace (天下太平 tianxiataiping)" this is should be the goal all the rulers hope to achieve, however, it depends on the ruler's attitude towards enlightenment. If a ruler can deeply feel the precious of virtue, he will naturally pay attention to the importance of teachings, as ChuanShan said:

Understand the precious of virtue, so respect and advocate the principle of teachings, use them widespread to enlighten among the people, and create virtuouspowers, this officials are not unjust, and the country is governed. (Wang, 2011a, p. 517)

If virtue was highlighted among the world, then people will become good day by day, and good customs will be completed. (Wang, 2011a, p. 870)

The so-called “respectthe virtue” achieved, then “admirevirtuous people (尚贤 shangxian)”, and the country that can make good use of the virtuous people will be able to governed and positive. Therefore, ChuanShan would say "teachings asthe basis of virtue"; "respecting virtue” is the foundation of the ruler's enlightenment.

However, the enlightenment, apart from "respecting virtue”, the ruler's own virtue is also very important. The so-called "virtuecompleted in top and enlightenment transform in bottom" and "teachings executed in top and good customs will be complete in bottom" (Wang, 2011a, p. 1171). This means is that emphasizing that if the ruler himself is a virtuous man like Yao and Shun, the result of his enlightenment will be quicker and more utility, 
and even the situation of "elimination of disputes, without speaking" and world be peace will be achieved. As ChuanShan said:

Elimination of disputes, without speaking, is lay down instructions in accordance with the marvelous way (神道设教 shendaoshejiao), from a superior person. (Wang, 2011f, p. 331)

This is equivalent to the "spheres of living (境界 jingjie)" of the so-called "the place where of a superior person influenced by his spirit, and where the people of there will be transformed”. But this can only be achieved by the "ruler who has the saint virtue (圣德之君王 shengdezhijunwang)". Therefore, the enlightenment of “humanity,music,penal,administration (礼乐刑政 liyuexingzheng)” and so on can only be regarded as a negative measure. However, the most fundamental and effective positive enlightenment comes from the virtue of the self-ruler. For example, the period of Yao and Shun, it is the real time can achieve the situation of elimination of disputes, without speaking, and world be peace.

That is, ChuanShan thinks that the purpose of enlightenment is nothing more than to make people can change physical endowment, understand the principle and further to explore the truth of the world, in order to complete the virtue and hair glow your speciality to accomplish its effectiveness for the world, send everyone in enlightenment naturally return the nature of its own goodness, and thus can "enlighten the people and complete good folk customs", so that the social atmosphere become good and harmonious. In this way, the people will do notdispute, the society will be harmonious and good, and the calamity will not happen, the country will in peace and positive. In other words, the purpose of "classic enlightenment" is not to impose something external to people, such as the so-called "indoctrination (灌输 guanshu)" education misunderstood by some modern scholars. On the contrary, it is intended to inspire "the original nature" that human nature itself already possesses, and through these classical enlightenment, it can also achieve the utility to of cultivating personnel, improving social atmosphere and even creating a harmonious atmosphere in the country.

\section{The Content and Methods of Classic Enlightenment}

What is the best content of the classic enlightenment? Wangfuzhisaid:’Theteachings of Six Confucian Classics (六经 liujing) is all about exhaustively studyprinciple and fully develop one's nature, nature is satisfied, the people of made teachings get the real means, enlighten learners rule of most equilibrium and highest just. So people all get their highest goodness of nature grow up, develop good folk customs. If classic is positive, the commonpeople will beenlightened,the heresy and improper theory do not influence and disturb him” (Wang, 2011a, p. 1173). The best teachingcontent of enlightenment is the Confucius by the modify and preparation (删 定shanding) of the “Six Confucian Classics”, because the contents of the sage personally validated is the best, it can guide learners to study the most equilibrium and highest just of principle, send people can understand the truth of the world, give full play to the inherent nature of human beings, and thus can achieve the goodness of the social atmosphere, then the different and popular theory do not disturb his strong will and confidence.

That is to say, for Wangfuzhi, since the sagemodified and prepared "Six Confucian Classics", all the truths of cosmic and life have already been implicated in them; therefore, it is certainly the bestcontent to enlighten them is the "Six Confucian Classics", because itcan improve one who change the physical endowment, in order to complete his natural powers.As he said: 
Confucian modified 《The book of songs》(诗经shijing) and《The book of history》(尚书shangshu), prepared Rite and Music,reestablishment of the “rule of Monarch (百王之大法 baiwangzhidafa)”. Fully develop many principles of things of the Heaven and Earth. (Wang, 2011e, p. 477)

From sagemodified and prepared, the way of enlightenment are fully developed in Six ConfucianClassics, the ruler and teachers use it as teachings, send learner be accustomed and conserved to it. The effective of changing the physical endowment, in order to complete his nature is like this. (Wang, 2011a, p. 1172)

Hethinks that all the enlightened content of the sage have been contained in the Six Confucian Classics, and people just need to chants and conserve "the classic texts (经典jingdian)", and the truth of world as time passes will spontaneously emerge from the mind come very naturally.As if Wangfuzhi himself said:

All principle of the world is inherent in our mind, conserveit with deep and long time, then principle of mindgrow up naturally. (Wang, 2011e, p. 1019)

The reason why classic texts is classic is that it contains the truth of cosmic and life. It penetrates into the common feelings and common principles of human life, so as to transcend time and space and for a long can't decay. It inspires common sense of human life and guides people to recognize virtue and goodness and other life's common principles. As long as people read these classic texts chants and conserve in it, they can understand the truth of the world. Because the classic texts itself is open, it contains a numinousprinciple, and abroad field of vision. It is up to these eternal texts to inspire you to conserve your nature and emotions, increase your wisdom, elevate your horizons and enhance your moral courage. In other words, when choosing enlightenment content, these "most valuable books" and "eternal books" of the "Six ConfucianClassics" are the most suitable, because there is a great secret behind them about the fullness of human nature (Kant,2005, p. 6).

On the other hand, Wangfuzhi also advocated “Articlecontains the Dao (文以载道 wenyizaidao)” and “Behold the Dao through the Article, (即文见道 jiwenjiandao)”. Therefore, people can also hear and see the Dao through chanting and reading these texts, and then learn these principles. As he said:

Illustrious Dao by speaking, Dao is fully developed in the speaking. (Wang, 2011h, p. 925)

The teachings of sageare only forexhaustive study of principle through the things and behold the Dao through the Article. (Wang, 2011h, p. 570)

Article is all the words contain the Dao, otherwise, it can also explore Dao. (Wang, 2011h, p. 470)

That is to say, Confucius's made teachings are all fully developed in the Six Confucian Classics. The content of "The Six ConfucianClassics" contain the truth of the world spoken by the sage, and as long as most people chant and conserve it about these classics for a long time, then the truth can naturally be reflected. The so-called "reading the books a hundred times, its meaning naturally be displayed". This is the reasons.

As for the teaching method?Wangfuzhi is so advocated:

The way of nurtureMeng (蒙 meng), connecting to the way becoming sage, if he doesn’t like to do on mind, even if he is forced, he cannot persist on one day. Because of that, learner should trust stable their emotion, and teacher guide him by the nature. (Wang, 2011b, p. 139)

That is, the teaching method must be capable of conforming (顺导 shundao) to human nature, neither in a forced manner, it is by the nature. Otherwise, even if you barely teach it, the short-time people can barely obey, 
but over time, people naturally very annoying. In particular, children are purely natural and their preferences are straight forward. If you insist on imposing something they do not like, not only fail to achieve the desired effect, it will distort their nature and emotion.

In other words, education is taught in the most natural, simple, and enjoyable way according to the laws of human development. Culture belongs to a kind of "edification (熏陶 xuntao)", it belongs to a "move then to change gradually (潜移默化 qianyimohua)”. It is not understand the time immediately, rather than to use it immediately. It is to be preservation in a person's mind, so that in his lifetime, slowly to develop and slowly “practice and enlightenment (体悟 tiwu)". There is no need to force it. Just guide it and let it take it naturally.

Therefore, we say that the content of "classic enlightenment" should be based on the "Six Confucian Classics" because itcontain the truth of mankind, with eternity, openness and timely. It can conserve people's nature and emotion, raise people's wisdom, heighten people's horizons, enhance people's moral courage and so on. In teaching methods, it is also taught in the most natural and simple "conforming” way, so that people who are learning naturally like the classics texts and step by step to get edification from itcan achieve an effect to move and change gradually their nature and emotion. Therefore, it will not, as some opposed scholars put it, that classical enlightenment is "ideas contrary to scientific" and "retro-retrogressive education" and "going to an ignorance of cultural conservatism (保守主义baoshouzhuyi)”.

\section{The Timing of the Classic Enlightenment}

As Wangfuzhi advocated, "to cultivatetheir mind of becomingsagein Meng, then it will be the foundation of becoming sage". "The way of nurtureMeng, is connecting to the way becoming sage". People should be able to give fully play to their nature, send further to “become a sage and worthies (成圣成贤 chengshengchengxian)”. Its teachings and guidance must begin with children. Because he thinks that during the period of Meng, is the time in a “when he feels he wants to wake up and he cannot wakes himself up (欲觉未觉yujueweijue)”, and feel “wants to strive and struggle (愤悱之时fenfeizhishi)”. Only after having good guidance and inspiration can they move forward in a right and positive direction. As he said:

Why Mengprosper (亨 heng), because when he is in ignorance, he pursue light (阳 yang)and get developed from the hoodwinks, by virtue of the due medium (中道 zhongdao) to prevent stupid and false, when the time he feels he wants to wake up and he cannot wake himself up, and feel want to strive and struggle, can pursue prosperitydevelop, not self-imposed. (Wang, 2011g, p. 100)

Children's understanding of life is the time in ignoranceand feels wake up but cannot wake himself up; it is the time need for people to be guided andinspired to make life unimpeded.

On the other hand, he also thinks that if children are allowed to develop naturally without proper guidance, they should be taught what they should be educated. They will be confuse and do not know where to go, it will float like a boat in the boundless sea, do not know which direction to go, so it will drifting long, aimless like wild horses running around, chaos, until they grow up, they may become stubborn and perverse and do nothing. As Kant said, meeting all the headstrong demands of children as a child will corrupt their ambition and morality. Young children still have no concept of morality. Once theirnatural endowments of material force are corrupted, they must rely on very severe punishment to reverse them (Kant, 2005, p. 19). That is, if there is no good enlightenment and guidance during childhood, it will be very difficult to educate and change when he grow up. 
As Wangfuzhi himself said:

Meng, is an adjective that grasses and flowers grow thickly and messy, when cannot distinguish from confounding of them. Why we call child a Meng? For instance, unlike birds and beasts born with ability of nature, they have the latent quality of bright, when they grow up, they became stubborn and perverse, but when people are still child, obscure and ignorant. Reasons have not yet formed, desire is also limit him don't be indulgence. When Meng encounters dangerous thing, we will stop him. Repress preserve behavior with not strict or easy, it is what prevention of education. When you should inform him, inform him, when you should not inform him, do not inform him. Standing in the due medium, let them learn it themselves. This is the right way to teach Meng, useful for them. (Wang, 2011g, p. 100)

That is, educate children should not be allowed to develop freely as many people in modern times advocate. It is advisable not to set goals for them and to make them do what children are happy to do. Butif you want to make a person's nature and emotionget positive, so that they can learn spontaneously they must begin to be educated from childhood. As Kant said: “Discipline (规训 guixun) must be exercised as soon as possible, and later it is hard to change one, and it will always be self-willed, so one must be accustomed as soon as possible to placing himself under the rules of rationality. When he is a young man, letting go of one's own course without deterrence, he will have some wildness for life" (Kant, 2005, p. 4).

That is to say, Wangfuzhi advocated that one should develop good habits and a correct concept of life and must begin to enlighten them from childhood. Because his ambition has been established when you begin to enlighten him, you guide him to recognize thedirection of wise, andhighest excellence of original nature, he naturally will gradually go in that direction to explore and work hard. If you lead him to the unhealthy populars, or leave him live in a common harmful customs without any right leadings, then he will flow in despicable and vulgar without know it unconsciousness, as Wangfuzhi said:

What learner use to learn, what teacher use to teach, they all havewhat they should to do. At the time you first started educating him, the child's aspiration were determined. Guiding him with vulgar customs and fashions, he will flow in despicable day by day, and there is no way to stop. Guiding him with great theory of "nature and mandate (性命 xingming)", he will thinks very highly of himself, but it's not real. It only follows nature of his own accord, add must-practice things, and fully develop he can do, teacher teach it, learner also learn it. (Wang, 2011h, p. 255)

To complete the natural powers must begin in childish, especially for who wants to become sage and worthies, which must be properly inspired and guided in childhood. From an early age, they should be exposed to the most wisdom texts and inspire them to set their big ambitions and goals. Don't tolimit and force their and utmost to promote their development in an infinitely possible direction. As Wangfuzhi himself said: "the enlightenment of Meng should not be forced to a small achievement, otherwise, it will make they be limited of wise, thenambition and ideanot clear and resolute, he will in superficial and despicable all their life” (Wang, 2011a, pp. 717-718). Don't just be satisfied with play with clever and little achievement, otherwise you will limit their road to wisdom and highest excellence. They will only stay on the knowledge of superficial and despicable and without knowing it unconsciousness for life.

\section{conclusion}

For Wangfuzhi, although the original nature of humanity is pure and highest excellent, but to complete nature is not in one go. It is a process of nature grows daily and achieves completion daily", "complete nature 
must basics to inherit goodness”, “complete nature with your practice”. Therefore, "posterior humanistic (后天 人为houtianrenwei)” enlightenment is very important. And he thinks that the purpose of enlightenment there are four: (1) illustrious Dao and exhaustively study of principle, in order to fully develop one's nature; (2) change the physical endowment, in order to complete his natural powers; (3) complete virtues, in order to highlight his nature adequately; (4) enlighten people and complete good folk customs, to eliminateof disputes, without speaking. In other words, he thinks the purpose of enlightenment is nothing more than to make people can change the physical endowment, understand the principle and further to exhaustive study the truth of the world, in order to complete the virtue and hair glow the one's speciality to accomplish effectiveness for the world, so that everyone in enlightenment naturally return the nature of its own goodness, and thus can "enlighten the people and complete good folk customs," so that the social atmosphere become good and harmonious. In this way, the people will do not dispute, the society will be harmonious and good, and the calamity will not happen, the country will in peace and positive.

What should be enlightened as the content is the best? Wangfuzhi advocated: "The teachings of Six Confucian Classicsare all about exhaustively studyprinciple and fully develop one’s nature, nature is satisfied, the people of made teachingsget the real means, enlighten learners rule of most equilibrium and highest just. So people all get their highest goodness of nature grow up, develop good folk customs, because if classic is positive, the common people will be enlightened, the heresy and improper theory do not influence and disturb him.In other words, he thinks that the best teaching material is the "Six Confucian Classics" that were personally modified and prepared by Confucius. The content of the textbooks was approved by the sage in person. Therefore, it is the best that can guide learners to study the principle of rule of most equilibrium and highest just, enable people to understand the truth of the world, give full play to the inherent nature of human beings and then achieve the goodness of social atmosphere, even in the different and popular theory do not disturb his strong will and confidence.

But what is the best time to begin enlightenment? In the case of Wangfuzhi, "to cultivatetheir mind of becoming sage in Meng, then it will be the foundation of becoming sage", "The way of nurtureMeng, connecting to the way becoming sage”. In other words, people should be able to give full play to their nature and then become sageand worthies,complete natureand natural powers, its inspiration and guidance, we must start from children. Because he thinks that during the period of Meng, people were in a "when he feels he wants to wake up and he cannot wakes himself up, and feel wants to strive and struggle”. Only after having good guidance and inspiration can they move forward in a right and positive direction.

Above, although Wangfuzhi's classic enlightenment thought has been hundreds of years away from today, his thinking on the issues involved is still quite worthy of reference and reflection by contemporary people.

\section{References}

Kant, Zhao, P., \& He, Z. W. (2005). Vorlesungenuber Padagogik. Shanghai: Shanghai Century Publishing Group.

Wang, F. Z. (2011a). Commentaries on the book of rites. Hunan: publisher's name.

Wang, F. Z. (2011b). Commentary on Master Zhang's a correct discipline for beginners. Hunan: Yuelu Publishing House

Wang, F. Z. (2011c). Comments on the comprehensive Mirror for Aid in Government (Volume X). Hunan: Yuelu Publishing House

Wang, F. Z. (2011d). Complete works of ChuanShan-Extended interpretation of the book of history. Hunan: Yuelu Publishing House. 
Wang, F. Z. (2011e). Discussions after reading the great collection of commentaries on the fourbooks. Hunan: Yuelu Publishing House

Wang, F. Z. (2011f). Extensive commentary on the book of songs. Hunan: Yuelu Publishing House.

Wang, F. Z. (2011g). Inner commentary on the book of changes. Hunan: Yuelu Publishing House.

Wang, F. Z. (2011h). Interpretation of exegetical from collected commentaries on the four books. Hunan: Yuelu Publishing House. 